\title{
A Prospective Study for "Developing School Based Model for Mainstreaming Rational Use of Medicine"
}

\author{
Yashashri C. Shetty ${ }^{1}$, Nirmala N. Rege ${ }^{1}$, Amol E. Patil ${ }^{1}$, R. R. Shinde ${ }^{2}$, \\ Seema S. Bansode-Gokhe ${ }^{2}$, Paresh Koli ${ }^{1}$, Smita Brahma ${ }^{{ }^{*}}$ and Indira Shukla ${ }^{3}$ \\ ${ }^{1}$ Department of Pharmacology and Therapeutics, Seth G. S. Medical College and KEM Hospital, \\ Mumbai-400 012, India. \\ ${ }^{2}$ Department of Preventive and Social Medicine, Seth G. S. Medical College and KEM Hopsital, \\ Mumbai, India. \\ ${ }^{3}$ Gokhale College of Education and Research Centre, Parel, Mumbai, India.
}

Authors' contributions

This work was carried out in collaboration between all authors. All authors read and approved the final manuscript.

\section{Article Information}

DOI: 10.9734/BJPR/2016/29470

Editor(s):

(1) Syed A. A. Rizvi, Department of Pharmaceutical Sciences, College of Pharmacy, Nova Southeastern University, USA.

Reviewers:

(1) José Eduardo Martinez, Pontifical Catholic University of Sao Paulo, Brazil.

(2) Joseph O. Fadare, Ekiti State University, Ado-Ekiti, Nigeria.

Complete Peer review History: http://www.sciencedomain.org/review-history/16686

Original Research Article

Received $12^{\text {th }}$ September 2016

Accepted $7^{\text {th }}$ October 2016

Published 27 $7^{\text {th }}$ October 2016

\section{ABSTRACT}

Background and Objectives: For mainstreaming rational use of medicines (RUM), consumer education is a must. It was felt that a school based model, developed to empower teachers regarding RUM using a modular programme, can generate advocates to influence students as well as parents. The present study was undertaken to assess the baseline knowledge of school teachers about RUM and for pilot testing of some of the modules.

Place and Duration of Study: Gokhale College of Education \& Research, Parel, Mumbai and Department of Pharmacology \& Therapeutics, Seth Gordhandas Sunderdas Medical College \& King Edward Memorial Hospital, Mumbai. From March 2013 to December 2013.

Materials and Methods: After obtaining IEC approval and informed consent, 96 final year B.Ed teachers were administered a validated questionnaire having total 60 questions, based on the information to be given to a doctor, sought from a doctor and enquiries to be made while purchasing medicines. Questions related to the attitude and behaviour like self prescribing, 
antibiotics use, treatment for common diseases like cold, cough and diarrhoea, and use of multivitamins were also included. Participants were then given the above-information using powerpoint presentation, followed by group discussions and personal medicine inventory assessment. Post-test was conducted and the data was analysed using Wilcoxon matched pairs test.

Results: 70/96 participants filled the personal inventory assessment proforma. Of these 63 carried drugs with them, crocin being the commonest. Of these, only 25 participants had knowledge of drug name in the brand they were using. The basal knowledge scores of $64 \pm 13.15$ showed significant improvement to $74.78 \pm 11.66$ post-workshop $(p<0.05)$. This was mainly in areas like history giving of chronic disease/family disease (25\%), pregnancy, contraception and habits (21\%) and information to be sought about side effects and lifestyle modifications (20\%). Awareness about rational injection use (31\%) and treatment of diarrhoea and cough (15\%) was also increased. The modules were well accepted. Desire for repeated training sessions was expressed by the participants.

Conclusion: Knowledge of school teachers regarding appropriate use of medicines was insufficient but they were receptive towards training.

Keywords: Rational use; medicine; school teachers; children.

\section{INTRODUCTION}

World Health Organization in 1985 defined rational use of drug, as the use of medications appropriate to a patient's clinical needs, in doses that meet their own individual requirements, for an adequate period of time, and at the lowest cost to them and their communities [1]. This concept can however be implemented, only if the process of prescribing and dispensing are appropriately followed and a proper diagnosis and correct information is conveyed to the patient [2].

In contrast, irrational use of medicines, includes cases in which medicines are prescribed when none are needed, medicines are not prescribed according to Standard Treatment Guidelines (STGs), ineffective or unsafe medicines are prescribed, effective and available medicines are underused or medicines used incorrectly [2]. Polypharmacy, inappropriate use of antibiotics and overuse of injections are the most common form of irrational use of drugs [1].

One of the most cost-effective medical interventions ever known is, the medical treatment with drugs. This is reflected in the proportion of national health budget spent on medicines ranging from $10-20 \%$ for developed countries followed by $20-40 \%$ in developing countries [3]. Currently, more than $50 \%$ of the medicines prescribed worldwide are prescribed, sold or dispensed incorrectly and about $50 \%$ of patients take them incorrectly. The greater magnitude of this problem exists in the developing and transitional countries. In these countries less than $40 \%$ of patients in public sector and less than $30 \%$ of patients in private sector are treated in accordance with the Standard Treatment Guidelines. Even in the Indian scenario, inappropriate use and over- use of medicines is a waste of scant resources and is often an out of-pocket expense to the patients. Such practice can lead to inappropriate patient demand, medicine stock-out and loss of public confidence on health system [4].

Harmful consequences of irrational use of medicines include unnecessary adverse events, rapidly increasing antimicrobial resistance (due to over-use of antibiotics) and the spread of blood-borne infections such as HIV and hepatitis $\mathrm{B}$ or $\mathrm{C}$ (due to unsterile injections) all of which cause serious morbidity and mortality and cost billions of dollars per year [5].

Considering the alarming consequence that irrational use of medicines can have on the community, various interventions have been put forth for rationalising the use of drugs. The persons who may contribute to the chain of irrational drug use include administrators, Pharmaceutical managers, prescribers and consumers themselves. The Governments have a responsibility to ensure that, both the quality of medicines and the information regarding these medicines, are made available to consumers. These include various educational materials to prescribers like Standard Treatment Guidelines, newsletters, bulletins, group discussions, seminars, workshops, effective package labelling etc. These interventions are mainly directed towards the prescribers. However, poster 
display, exposition, slides, radio programmes, theatre, leaflets and demonstration marches are some of the strategies used for public education regarding rational use of medicines [6].

The knowledge, attitude and education of public in relation to disease etiology and treatment serve as vital determinants in patients decision to seek health care, choice of healthcare provider, use of drugs and success of treatment. Public education provides information to individuals and communities which enables them to make an appropriate, safe and judicious use of medicines [2].

The toughest challenge to treatment of a disease is, procuring the medicines and adhering to the prescription. Doctors often prefer that patients enquire about the medicines prescribed and give intricate details of their disease and comorbidities and that patients should seek all clarifications about the prescription and avoid substitution of medicine by pharmacist [7].

In developing countries like India more than 31\% population is under the age of 15 [8]. Schools are considered as the second home for children and it is thought that health education provided by teachers will immediately influence health behaviours of children, persisting into adulthood. Moreover self medication among adolescents is one of the critical aspects of irrational use of medicines [9]. Children are exposed to medicines in day to day life by observing family members, visiting pharmacy shops, watching television and other media [10]. A Kuwait study reported that teachers consider it important to imbibe principles of rational use of medicines amongst children and that it should be a part of school curriculum [11]. Also a study in Poland concluded that community acquired infections can be reduced if relevant education is provided in primary and secondary schools [12]. Furthermore significant improvement was noted in knowledge of antibiotics, vitamins and cough management after school teachers were educated through different modes [13].

The group which can influence the students the most and inculcate in them appropriate values of Rational use of medicine are teachers, who are also the consumers. Teachers are considered to be learned, respected members of local communities and through whom knowledge of rational use of medicines can be disseminated to children, parents and entire community. They can also serve as an effective channel for propagating this knowledge.

Hence, our study was planned, with trainee teachers in final term of B.Ed course about to serve as teachers, as target participants with the following objectives:

- To assess baseline knowledge among trainee school teachers regarding rational use of medicine.

- To develop and apply module on rational utilisation of drugs in the trainee teachers participating in the study.

- To invite suggestions from the teachers regarding use of the training session for school children and dissemination of the information in the community.

\section{MATERIALS AND METHODS}

The study was a prospective interventional questionnaire based study conducted from March 2013 to December 2013. All the questionnaires used in the study were validated from experts i.e., teachers of Gokhale College of Education \& Research, Parel, Mumbai and faculty members of Department of Pharmacology \& Therapeutics, Seth Gordhandas Sunderdas Medical College \& King Edward Memorial Hospital, Mumbai. Their inputs were incorporated in the final questionnaire used on the day of workshop.

Permission from Institutional Ethics Committee of Seth Gordhandas Sunderdas Medical College \& King Edward Memorial Hospital, Mumbai and administrative heads of the two institutes mentioned above was taken prior to study initiation. The intervention consisted of a workshop on rational use of medicines conducted in the auditorium of Gokhale College of Education \& Research.

96 trainee teachers who were in final term of B.Ed course were the participants of the workshop who were divided into 10 groups. Their written informed consent was taken following which they were administered a pre-training questionnaire consisting of questions pertaining to what information does a patient require to tell a doctor, what information does the patient need to ask the doctor, about prescribed medicines and enquiry to be made at the pharmacy. Further the participants were given a personal inventory assessment form to assess which medicines 
they carry with them and their knowledge of such medicines.

Later, a power point presentation of basic principles of rational use of medicines was given by one of the co-investigators of the study. Intermittently, based on the three modules of study i.e., to what information a patient should tell the doctor, what information the patient should ask the doctor about prescribed medicines and enquiry to be made at the pharmacy, the groups were asked to write their opinion and form a consensus amongst group. For each module, few group leaders were given an opportunity to express their opinion, which was followed by clarification of module by the coinvestigator of the study. Finally, the workshop was concluded with a post-training questionnaire and feedback questionnaire.

The presentation included the following:

1: Information the patients should tell the doctor

- Patient's problem in brief with chronological order.

- Whether allergic to any drugs.

- Whether suffered from jaundice in the past

- Whether suffering from chronic diseases like asthma, diabetes, anaemia, chronic diarrhoea, epilepsy (in case of adults with hypertension/any heart disease or diseases of liver, kidney and blood) or have been taking medicines for any other diseases.

- Whether he/she consumes alcohol/ smokes/chews tobacco regularly.

- Whether she is pregnant or a nursing mother.

- Whether she is on contraceptives.

2: Information they should seek from the doctor about the medicines prescribed

- About the diagnosis.

- Why aren't any drugs prescribed / How will the disease get cured without drugs? What parameters should be monitored at home?

- Why drugs have been prescribed, how many, at what time they are supposed to be taken and their doses, duration of therapy.

- When to follow up and how and when to stop.

- Common adverse reactions and what should be done.
- Any restrictions related to life style, diet, or other common drugs.

- Doctor's contact number/address for emergencies.

3: Information regarding the enquiries made while purchasing the drugs

- Check the license of the pharmacist in the shop (to check authenticity of pharmacist).

- Brand name given by the doctor and supplied by the pharmacist should be the same; if not consult doctor before purchasing (will preclude cost effective generic substitution).

- Manufacturing and expiry date and batch number.

- Intactness of the seal and blister pack.

- If the drug is in tablet / capsule, whether discolored/cracked; if in liquid form, check for suspended /floating material; if emulsion, creaming or cracking.

- Any instructions regarding storage and disposing of drugs.

- $\quad$ Insisting on cash memo.

- Any other clarification.

\subsection{Statistical Analysis}

Since, this study was conducted as a pilot study, no formal sample size calculation was done and all the 96 participants present, with their consent were included in the study. Descriptive statistics was used to analyse the percentage of positive responders for closed ended questions. Then Wilcoxon matched pairs test was used to determine the percentage improvement in each question as well as for overall percentage improvement of basal knowledge scores of all participants. While, all open ended questions were analysed as maximum percentage of particular opinion.

Statistical tests were applied as relevant by using the statistical software Graph Pad Instat DATASET1.ISD (Windows 7, Graphpad Software, San Diego California USA, www.graphpad.com).

\section{RESULTS}

96 trainee teachers participated in the workshop. Out of these 78 were females while 18 were males. 


\subsection{Personal Inventory}

The personal inventory assessment proforma was filled by $70 / 96(72.96 \%)$ participants. Out of these 70 participants, 63 carried at least one drug with them while the remaining 7 filled the proforma but did not carry a single drug with them in their purse or bags or wallets. The participants carried a wide array of drugs with them accounting to a total of 120 drugs possessed by the 63 participants. Out of these 120 drugs, the most common drug encountered was paracetamol which was carried by 41 participants. The other drugs which were carried by the participants consisted of aspirin, diclofenac, cetrizine, chlorzoxazone, dicyclomine, dicycloverine, calcium, ranitidine, omeprazole and certain medicines of Ayurvedic therapy.

Only $39.8 \%$ of the participants had answered the name of the company manufacturing the product they carried while $40.12 \%$ of participants were aware of the contents of the product. Out of the total 120 drugs encountered, the participants specified an indication for the product for 113 drugs. On $80 \%$ occasions, the indication specified was correct. For $78.8 \%$ of drugs, the participants mentioned use on, as and when required basis. Furthermore, for $62.5 \%$ drugs the source of drug was mentioned as pharmacy shop. Only $46.91 \%$ i.e. for 58 drugs the product was obtained with advise from the doctor while $18(15.25 \%)$ were self-prescribed and others included advise of mother, father, friends and advertisements.

\subsection{Pre-test and Post-test Assessment}

The pre-test and post-test comparative assessment revealed that the basal knowledge scores of all participants expressed as Mean \pm S.D was $64 \pm 13.15$ and it showed significant improvement to $74.78 \pm 11.66$ post-workshop $(p<0.05)$. It is represented in Fig. 1.

The question wise comparative assessment of pre-test and post-test data revealed that there was significant improvement in knowledge of questions as represented in Table 1. It was found that $19 / 60$ questions showed significant improvement.

Regarding assessment about general diseases commonly encountered, there was no significant improvement seen but some noteworthy points have been highlighted here.

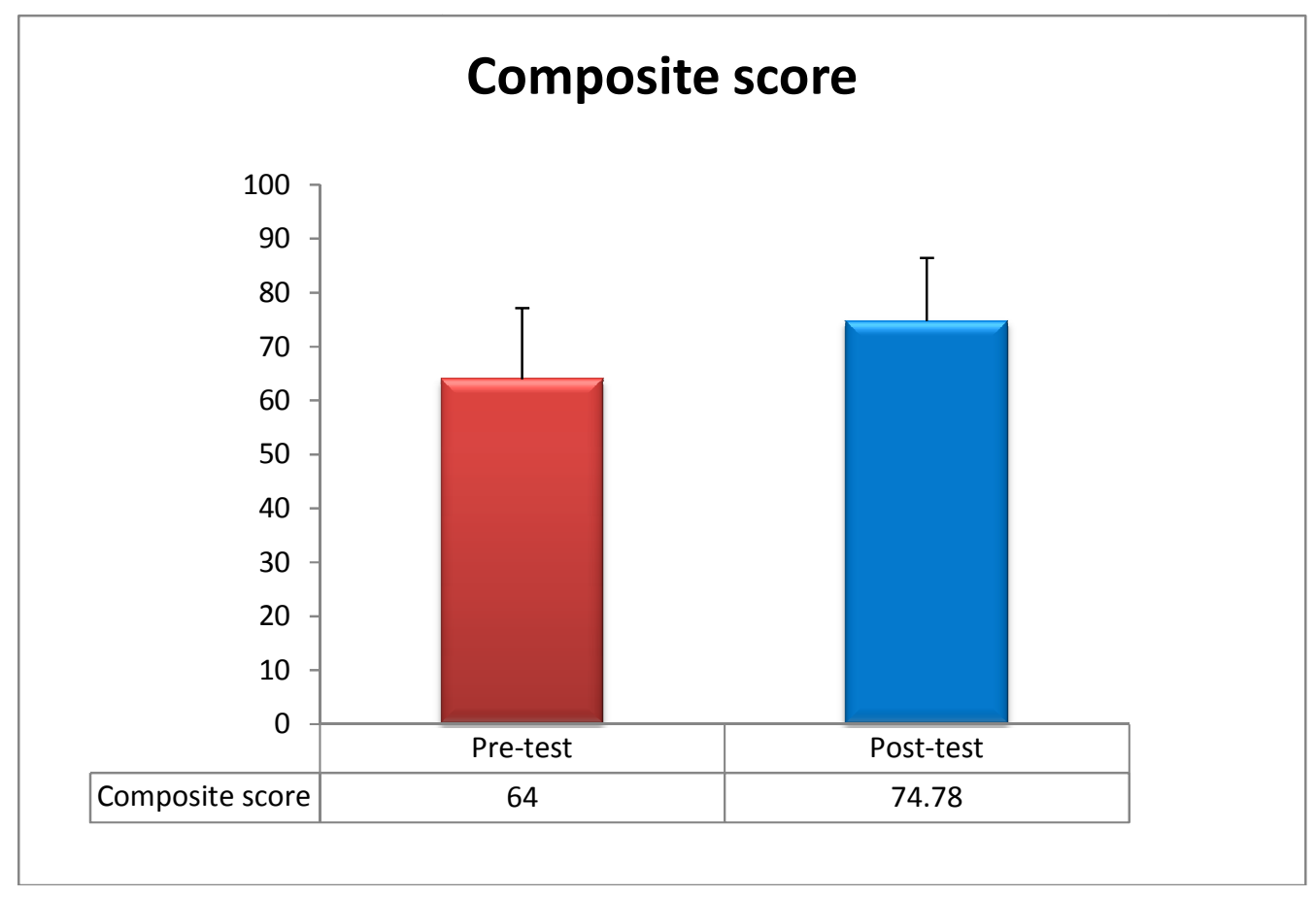

Fig. 1. Pre-test and post-test composite scores of participants $P<0.05$ using Wilcoxon matched pairs test 
Table 1. Question wise scores before and after the intervention

\begin{tabular}{|c|c|c|c|}
\hline Question & $\begin{array}{l}\text { Pre-test } \\
\text { (Percentage } \\
\text { with correct } \\
\text { answers) }\end{array}$ & $\begin{array}{l}\text { Post-test } \\
\text { (Percentage } \\
\text { with correct } \\
\text { answers) }\end{array}$ & p value \\
\hline $\begin{array}{l}\text { If yes, within how much time do you seek treatment? } \\
<24 \mathrm{hrs} />24 \mathrm{hrs} />2 \text { days } \mathrm{A} / \mathrm{B} / \mathrm{C}\end{array}$ & 32 & 53 & 0.0020 \\
\hline $\begin{array}{l}\text { Do you think it is important to inform doctor about } \\
\text { details of current illness? Y/N }\end{array}$ & 75 & 86 & 0.0484 \\
\hline $\begin{array}{l}\text { Do you think it is important to inform doctor about past } \\
\text { history of any chronic disease? } \mathrm{Y} / \mathrm{N}\end{array}$ & 65 & 90 & 0.0001 \\
\hline $\begin{array}{l}\text { Do you think it is important to inform doctor about past } \\
\text { family history of any disease? } \mathrm{Y} / \mathrm{N}\end{array}$ & 60 & 85 & 0.0001 \\
\hline $\begin{array}{l}\text { Do you think it is important to inform doctor about } \\
\text { alcohol consumption/smoking/chewing tobacco? } \mathrm{Y} / \mathrm{N}\end{array}$ & 53 & 74 & 0.0011 \\
\hline $\begin{array}{l}\text { If female, do you think it is important to inform doctor } \\
\text { about whether pregnant? } \mathrm{Y} / \mathrm{N}\end{array}$ & 60 & 82 & 0.0007 \\
\hline $\begin{array}{l}\text { If female, do you think it is important to inform doctor } \\
\text { about use of contraceptives? } \mathrm{Y} / \mathrm{N}\end{array}$ & 57 & 86 & 0.0001 \\
\hline $\begin{array}{l}\text { If female, do you think it is important to inform doctor } \\
\text { about history of abortion/miscarriage? } \mathrm{Y} / \mathrm{N}\end{array}$ & 60 & 84 & 0.0003 \\
\hline $\begin{array}{l}\text { Do you think it is important to ask doctor about the } \\
\text { diagnosis? } \mathrm{Y} / \mathrm{N}\end{array}$ & 79 & 93 & 0.0023 \\
\hline $\begin{array}{l}\text { Do you think it is important to ask doctor about the side } \\
\text { effects? Y/N }\end{array}$ & 74 & 92 & 0.0002 \\
\hline $\begin{array}{l}\text { Do you think it is important to ask doctor about the } \\
\text { restrictions related to life style, diet or other drugs? Y/N }\end{array}$ & 71 & 89 & 0.0049 \\
\hline $\begin{array}{l}\text { Do you think it is important to check the license of the } \\
\text { pharmacist in the shop? Y/N }\end{array}$ & 50 & 83 & 0.0001 \\
\hline $\begin{array}{l}\text { Do you think it is important to look out for the } \\
\text { instructions regarding storage? } Y / N\end{array}$ & 78 & 91 & 0.0071 \\
\hline Have you heard about antibiotics? Y/N & 74 & 89 & 0.0250 \\
\hline Resistance? Y/N & 43 & 73 & 0.0019 \\
\hline
\end{tabular}

$48 \%$ study participants considered cough as a disease. $65 \%$ of study participants failed to answer about the preference of treatment for cough. Even after training, $60 \%$ study participants considered cough as a disease. $61 \%$ of study participants failed to answer about the preference of treatment for cough.

$69 \%$ of study participants thought diarrhoea was a kind of severe disease \& $53 \%$ thought it was necessary to give antibiotics to treat it. $78 \%$ of study participants heard about the oral rehydration solution (ORS). $69 \%$ knew how to prepare it. However, after training $75 \%$ of study participants thought diarrhoea was a kind of severe disease \& $56 \%$ thought it was necessary to give antibiotics to treat it. $94 \%$ of study participants said they had heard about the ORS powder and $78 \%$ knew how to prepare it at home.
$55 \%$ of study participants thought multivitamins are drugs, $70 \%$ thought that they would provide more energy and make the body stronger. However, $65 \%$ thought there was no need to take multivitamins while on balanced diet. $49 \%$ of study participants were of the opinion that milk was an adequate source of iron. Finally, $85 \%$ of the study participants thought that medicines should be used only when prescribed by doctors.

Following training, however, some improvement was noted. $67 \%$ of study participants thought multivitamins are drugs, $67 \%$ thought they give more energy, $64 \%$ thought they will make body stronger. $63 \%$ thought there is no need to take multivitamins while on balanced diet. $49 \%$ of study participants thought that milk is an adequate source of iron. $90 \%$ of the study participants thought that medicines should be used only when prescribed by doctors. 


\subsection{Feedback Analysis}

The feedback analysis of the participants revealed that they almost got well versed with all the concepts discussed in the session. The participants responded that they would organize seminars, workshops, parent teacher meetings, camps and health education sessions to disseminate the information to students and community. Though, very few suggestions were obtained for improvement of session, few suggestions included more discussion on the concepts of common infectious diseases, mental disorders and gynecological disorders in young females.

\section{DISCUSSION}

Our study revealed that there exists an unawareness regarding the medicines which the participants carried along with them and also the information that the patient is expected to tell or ask the doctor and enquire at the pharmacy shop. The baseline knowledge scores showed significant improvement post-workshop. This improvement was seen in providing history of chronic disease/family disease, pregnancy, contraception and addiction and information to be sought about side effects and lifestyle modifications. The modules were well accepted and desire for repeated training sessions was expressed by the participants.

Our study group consisted of $81.25 \%$ females. This finding was significant as Anderson LB reported that female teachers have better selfefficacy and job-satisfaction as compared to male teachers [14]. Paracetamol was the most common drug carried by 41 participants in various brands like crocin, metacin, combiflam, saridon. But only 8 had the knowledge regarding the content of the brand and all except 9 had knowledge regarding the indication of the drug. Lack of knowledge regarding paracetamol content in the brands was quite similar to previous studies by Boudreau DM et al. [15] who reported inadequate knowledge of drugs containing paracetamol and Fosnocht D [16] who reported that only $66-90 \%$ of 1009 patients in emergency department in a USA hospital had knowledge regarding the paracetamol contained in the common brands. But, the fact that our study participants were educated, contributed to their better awareness regarding the indication for use of the brand. This was reflected not only in the correct indication mentioned for paracetamol but also for $80 \%$ of the other drugs.
In the present study, only $46.91 \%$ drug products were obtained with advise from doctor while about $15.25 \%$ were self prescribed and others were taken with advise from mother, father, friends or advertisements. Self-medication is associated with risks such as misdiagnosis, use of excessive drug dosage, prolonged duration of use, drug interactions and polypharmacy [17]. The consumer, by no means can judge the efficacy of a drug, which is ideally to be made by the physician rather than patient or their relatives [18]. So, lack of knowledge of brand content and hesitation to take doctor's advice were the chief concerns detected from the personal inventory assessment.

A study by Kafle KK [13] in 2010 in Nepal, proved that knowledge and practices of drug use by the community members had improved, following intervention given to school teachers through training and interactive discussions between teachers and school children. Another study, by Anttila KH [19] reported that $93 \%$ of school teachers thought that teaching about use of medicines should form a part of national curriculum of health education. Based on these studies, we included school teachers, as our target population.

The basal knowledge scores of $64 \pm 13.15$ showed significant improvement to $74.78 \pm 11.66$ post-workshop $(p<0.05)$. The knowledge regarding use of antibiotics and terms like resistance was significantly improved post-test. The improvement in knowledge on action of antibiotics and methods of administration was similar to the study by Kafle KK [13]. However, our study did not reveal significant improvement in knowledge of cough as a disease, its treatment and use of vitamins as drugs as reported by the same. This difference in findings was mainly because the study mentioned above also consisted of other intermediaries and communication through F.M. radio and interactive discussions.

There was significant improvement in knowledge of timing to seek treatment. This knowledge is crucial, as seeking health care at the earliest is vital in most instances with special consideration to Cardiovascular and Central Nervous System disorders. There was a significant improvement in awareness about the importance of giving any family history to the physician especially for diseases like coronary artery disease, diabetes, sickle cell anaemia and breast cancer etc. Since chronic alcoholism and smoking are the commonest lifestyle addictions leading to 
conditions like alcoholic liver disease and lung cancer [20] and as interactions of smoking with commonly used medications like oral contraceptives and insulin are a concern, awareness about informing the doctor regarding smoking and alcoholism can turn the tale of diagnosis and line of management [21]. Moreover, obstetric history inclusive of pregnancy, contraception and abortion give clue to the family physician regarding health risks to the patient and also refrains him from prescribing teratogenic drugs in early pregnancy [22].

Our study revealed significant improvement in awareness about the importance of asking their doctor about diagnosis, side effects of medications and lifestyle modifications. All these enquiries are vital to ensure appropriate treatment and compliance. A meta-analysis by Kinnersley $P$ revealed that interventions to patients in the form of written materials produced only small benefits in question asking and patient satisfaction. It stated that more benefit was obtained by targeting clinicians [23]. However, in India, due to an inadequate doctor to patient ratio i.e.1:1800, and a heavy patient load, the clinicians lack time to undergo such interventions and also fail to comply with the training [24]. Therefore, it was considered important to target a vital group of consumers i.e. school teachers. Also, the importance of knowledge improvement regarding checking for license of the pharmacist is important to ensure reliability of the person dispensing the medication.

Even before the training session started, $85 \%$ of teachers already considered that medicines should be used only when prescribed by doctors. But despite this general belief, their knowledge was lacking regarding some important elements for rational use of medicines. The improvement in some of these components was reflected posttest.

The feedback analysis suggested that the participants benefitted a lot from the workshop and their answers regarding techniques used to disseminate this knowledge to community put light on their interest and enthusiasm to propagate this message forward. Also, their suggestions regarding improvements in workshop reflected their thirst to enlighten themselves in this regard.

\section{CONCLUSION}

Knowledge of school teachers regarding appropriate use of medicines was insufficient which improved after the training session. But, the participants were receptive towards training.

\section{DISCLAIMER}

Dr. Y. C. Shetty has presented a poster on "A prospective study for developing school based model for mainstreaming rational use of medicines" in the National conference on health professional education from 26- $28^{\text {th }}$ Sept 2013 organized by $\mathrm{MEU} \& \mathrm{MCl}$ regional center at Seth GS Medical College \& KEM Hospital, Mumbai.

\section{COMPETING INTERESTS}

Authors have declared that no competing interests exist.

\section{REFERENCES}

1. World Health Organization Promoting rational use of medicines: Core components. WHO Policy Perspectives on Medicines no. 5. Document WHO/EDM/ 2002.3. Geneva, WHO; 2002.

Available: http://www.who.int/medicines (Accessed $4^{\text {th }}$ September 2013)

2. Rational Use of Medicines. Good Pharmacy Practice - I.PA. - C.D.S.C.O. W.H.O. India Country Office.

Available:ftp://203.90.70.117/searoftp/WR OIND/whoindia/linkfiles/GPP Rational Us e of Medicines.pdf

(Accessed $4^{\text {th }}$ September 2013)

3. Promoting Rational use of medicines. A Publication by World Council of Churches. Contact $^{n}$. 2006;183:1-32.

4. Promoting Rational Drug use under NRHM. Indian Medical Council Regulations; 2002.

Available:http://nhsrcindia.org/pdf files/res ources thematic/Medicine and Technolog y/NHSRC Contribution/Others/Promoting Rational Drug use under NRHM NHSR C WHO.pdf

(Accessed $4^{\text {th }}$ September 2013)

5. The World Medicines Situation 2011Rational Use of Medicines. World Health Organization.

Available:http://apps.who.int/medicinedocs les/m/abstract/Js18064en/

(Accessed $4^{\text {th }}$ September 2013)

6. Grand AL, Hogerzeil HV, Haaijer-Ruskamp FM. Intervention research in rational use of drugs: A review. Health Policy Plan. 1999; 14(2):89-102 . 
7. Holloway K. Newsletter of the international network for the rational use of drugs. INRUD News. 2009;19(1):1-50.

8. Global indicator of population. Available:http://kff.org/globalindicator/population-under-age-15 (Accessed $4^{\text {th }}$ September 2013)

9. Jha $N$, Bajracharya $O$, Shankar PR. Knowledge, attitude and practice towards medicines among school teachers in Lalitpur district, Nepal before and after an educational intervention. BMC Public Health. 2013;13(652):1-11.

10. Bankar MA, Dudhgaonkar SS. Promoting the proper use of medicines in rural school children of India. Int $\mathrm{J}$ Basic Clin Pharmacol. 2013;2(4):375-80.

11. Abahussain E, Matowe LK, Nicholls PJ. Self-reported medication use among adolescents in Kuwait. Med Princ Pract. 2005;14(3):161-4.

12. Pieokowska AO, Grzesiowski P. Progress towards implementing the e-Bug Project in Poland. J Antimicrob Chemother. 2011; 66(5):v77-9.

13. Kafle KK, Karkee SB, Shrestha N, Prasad RR, Bhuju GB, Das PL, Chataut BD. Community intervention to improve knowledge and practices on commonly used drugs. Kathmandu Univ Med J (KUMJ). 2010;8(29):29-34.

14. Anderson LB. Teacher diversity: Do male and female teachers have different selfefficacy and job satisfaction? 2011. Available:http://soc.kuleuven.be/io/egpa/H RM/bucharest/Andersen2011.pdf (Accessed $17^{\text {th }}$ September 2013)

15. Boudreau DM, Wirtz H, Von Korff M, Catz SL, St John J, Stang PE. A survey of adult awareness and use of medicine containing acetaminophen. Pharmacoepidemiol Drug Saf. 2013;22(3):229-40.
16. Fosnocht D, Taylor JR, Caravati EM. Emergency department patient knowledge concerning acetaminophen (paracetamol) in over-the-counter and prescription analgesics. Emerg Med J. 2008;25(4): 213-6.

17. Hughes CM, McElnay JC, Fleming GF. Benefits and risks of self medication. Drug Saf. $2001 ; 24(14): 1027-37$.

18. Hazards of self medication. Guidelines for Health Care.

Available:http://guidelinesforhealthcare.blo gspot.in/2009/08/hazards-of-selfmedication.html.

(Accessed $1^{\text {st }}$ October 2013)

19. Anttila $\mathrm{KH}$. Education before medication: Empowering children as medicine users. Available:http://wanda.uef.fi/ukuvaitokset/vaitokset/2006/isbn951-27-04072.pdf

(Accessed $1^{\text {st }}$ October 2013)

20. Kasper DL, Braunwald E, Fauci AS, Hauser SL, Longo DL, Jameson JL eds. Harrison's principles of Internal medicine. $18^{\text {th }}$ ed. New York: McGraw Hill Companies Inc; 2012.

21. Brunton L, Chabner B, Knollmann B, eds. Goodman \& Gilman's the pharmacological basis of therapeutics. $12^{\text {th }}$ ed. China: McGraw Hill; 2011.

22. Minkoff $\mathrm{H}$. The medical significance of the obstetric history. Am Fam Physician. 1983; 27(5):164-6.

23. Kinnersley $\mathrm{P}$, et al. Interventions before consultations to help patients address their information needs by encouraging question asking: Systematic review. BMJ. 2008; 337:a485.

24. Doctor population Ratio for India: The Reality. Indian J Med Res. 2013;137: 632-5.

(c) 2016 Shetty et al.; This is an Open Access article distributed under the terms of the Creative Commons Attribution License (http://creativecommons.org/licenses/by/4.0), which permits unrestricted use, distribution, and reproduction in any medium, provided the original work is properly cited.

Peer-review history:

The peer review history for this paper can be accessed here: http://sciencedomain.org/review-history/16686 